ISSN: 0213-2087 eISSN: 2444-7080

DOI: https://doi.org/10.14201/shhc202139209233

\title{
LOS ESTADOS MAYORES DEL EJÉRCITO ANTE EL 18 DE JULIO
}

\author{
The Spanish Army General Staff \\ and the $18^{\text {th }}$ of July Uprising
}

\author{
Arturo GARCÍA ÁLVAREZ-COQUE \\ Universidad Complutense de Madrid \\ https://orcid.org/0000-0002-6775-3336
}

Recibido: 20/04/2021 Revisado: 08/06/2021 Aceptado: 05/07/2021

RESUMEN: Después de una reflexión historiográfica sobre la relevancia del estudio de los militares de 1936, tratamos como estudio de caso al grupo de jefes de los estados mayores. Es bien sabido que sólo tres de los doce generales de división con mando de tropas se sublevaron en julio de 1936. Algunos autores han sostenido que los jefes de los estados mayores (en un nivel jerárquico inmediatamente inferior a los generales) participaron mayoritariamente en la conspiración de la primavera de 1936, y que su papel fue clave allí donde la sublevación triunfó. En este artículo se demuestra que, por el contrario, fue minoritaria su participación en la conspiración. Fue asimismo una minoría entre ellos la que se sublevó en un primer momento, aunque finalmente todos menos tres terminaron uniéndose a la rebelión contra el Gobierno. Hemos considerado como causa de los errores historiográficos la posible pervivencia de una visión simplista sobre las actitudes de los militares ante la crisis de julio de 1936.

Palabras clave: guerra civil; militares; Estado Mayor; conspiración; sublevación; 18 de julio.

ABSTRACT: We discuss the relevance of the study of the officer corps in the Spanish army in 1936. Then we develop a case study on the group of the General Staff. It is well known that out of twelve generals, commanders of the main Army divisions, only three rebelled against the Government in July 1936. Various 
authors have claimed that most of the Staff's colonels (just below in hierarchy to the general commanders of the organic divisions) were involved in the Spring of 1936 conspiracy against the Republican Government, and moreover claim they had a key role wherever the July military uprising was successful. In this article we establish, on the contrary, that only a minority of them were involved in the conspiracy. Likewise a minority of them were initially part of the rebellion, even if all but three finally joined the rebels. We also discuss the persistance of a simplistic view on the attitudes of the army officers with respect to the July $18^{\text {th }}$ uprising.

Key words: civil war; military; General Staff; conspiracy; military uprising; July $18^{\text {th }}$.

\section{INTRODUCCIÓN}

En el estudio de la guerra civil española predominan los enfoques desde la historia política y social, o se enfatizan aspectos sin duda centrales, como el contexto internacional. También se ha profundizado en el papel de los individuos, a través de la biografía y de la literatura memorial. Por otra parte, como ha señalado Puell ${ }^{1}$, en la producción historiográfica sobre el conflicto ha tenido un peso bastante menor la faceta militar, de fundamental importancia. La guerra civil se dirimió en última instancia en los campos de batalla y culminó con la victoria de un ejército sobre otro ${ }^{2}$.

En general, la historiografía militar sobre la guerra civil se ha centrado en las campañas, las batallas, las estrategias, el armamento, o las relaciones entre la política y las operaciones militares. Pero no ha profundizado sobre quienes hicieron la guerra en primera línea, y en buena medida la provocaron: el cuerpo de militares profesionales. Por definición, los militares fueron el grupo protagonista de la contienda, en el campo de batalla o en los estados mayores (EEMM), siendo objeto muchos de ellos de diversos grados de depuración y violencia.

En la producción historiográfica de temática militar sobre la guerra civil, destacan los trabajos clásicos de J.M. Martínez Bande sobre las campañas militares, y los de Ramón Salas Larrazábal y Michael Alpert sobre el Ejército Popular de la Republica (EPR), destacables, entre otras razones, por el abandono de una visión maniquea de la guerra civil en favor del estudio de la abundante documentación en los archivos militares ${ }^{3}$. La obra de Salas (1. ${ }^{a}$ ed. 1973) trata de la evolución

1. Puell de la Villa, Fernando, Nuevos enfoques y aportaciones al estudio militar de la guerra civil, Iugm/uned. Salamanca: Ediciones Universidad de Salamanca, 2014, p. 96. Tomando como muestra los catálogos de cinco bibliotecas importantes, apenas un quince por ciento de libros de temática bélica o militar en títulos publicados entre 2006 y 2014, incluyendo memorias de combatientes.

2. Gabriel Cardona, en el prólogo de su libro sobre las operaciones militares afirma que su propósito era "pensar sobre la cuestión menos reflexionada de la Guerra Civil, que es la guerra misma" (CARdona, Gabriel, Historia Militar de una guerra civil. Barcelona: Flor del Viento, 2006, p. 20).

3. Martínez Bande, José Manuel, Monografías de la Guerra de España, Servicio Histórico Militar. Madrid: Ed. San Martín, 1968-198; Salas, Ramón, Historia del Ejército Popular de la República, Vols. I 
orgánica del ejército republicano a través de los cambios políticos y de las diferentes campañas a lo largo de la guerra. Proporciona datos sobre un elevado número de jefes y oficiales del ejército republicano, tanto profesionales como procedentes de milicias, aunque se limita a reseñar con menor o mayor detalle su actuación en la contienda ${ }^{4}$. El libro de Alpert $(1976,2007)$ no es tanto una historia del EPR como el de Salas, sino una extensa monografía sobre aspectos como el papel de las milicias, de los comunistas, o los aspectos internacionales. Alpert trata brevemente del Ejército de 1936 y aborda el papel de los militares profesionales en el EPR, con estimaciones sobre la distribución de la oficialidad entre los dos bandos. Incluye una reflexión sobre las actitudes de los militares, en particular sobre la idea de «lealtad geográfica», pero señala la dificultad de llegar a conclusiones fiables en una época en que todavía no eran fácilmente accesibles los fondos de archivo relacionados con los juicios militares de la posguerra.

En investigaciones más recientes se ha puesto de relieve la importancia del estudio de los militares de 1936 como grupo, para comprender el inicio, desarrollo y desenlace del conflicto ${ }^{5}$. Fuentes de particular relevancia son las causas abiertas por los tribunales militares contra los jefes y oficiales que no se sumaron o mostraron actitudes ambiguas ante la sublevación. El estudio de los militares profesionales requiere una perspectiva de conjunto, inclusiva de toda la oficialidad de $1936^{6}$ o de segmentos significativos de ella, que evite adoptar como referencia a unas pocas individualidades destacadas. Ejemplo paradigmático de éstas son los generales Rojo y Miaja, prácticamente los únicos militares en el bando republicano conocidos por el gran público, e incluso por parte de los especialistas de la guerra civil.

Uno de los trabajos sobre la oficialidad del 1936 a los que hemos aludido, trata el papel de los militares de Estado Mayor (EM) ${ }^{7}$, sector de élite del Ejército compuesto en julio de 1936 por 496 jefes y oficiales ${ }^{8}$. El presente artículo considera

a IV. Madrid: La Esfera de los Libros, 2006 (1. ${ }^{a}$ edición 1973); AlPERT, Michael, El Ejército Popular de la República, 1936-1939. Barcelona: Crítica, 2007 (1. a edición, Ruedo Ibérico, 1976). 264).

4. Por otra parte, Salas proporciona estadísticas de adscripción a cada bando (SALAS, op. cit. p.

5. Bahamonde, Ángel, Madrid 1939. La conjura del coronel Casado. Madrid: Cátedra, 2014; García Álvarez-Coque, Arturo, La fractura del Ejército ante el 18 de julio. El Estado Mayor en la guerra civil. Granada: Comares, 2018; Ruiz Llano, Germán, Militares y Guerra Civil en el País Vasco. Leales, sublevados y geográficos. Bilbao: Eds. Beta, 2019. Sobre las actitudes de los militares, son relevantes, Puell, Fernando, "Julio 1936, ¿un ejército dividido?». En: MARTínez ReverTe, Jorge, M (coord.), Los militares españoles en la Segunda República. Madrid: Ed. Pablo Iglesias, 2012; PuElL, Fernando, "La trama militar de la conspiración", en: SÁnchez PÉRez, Francisco, Los mitos del 18 de julio. Barcelona: Crítica, 2013.

6. En este sentido, una obra pionera es Engel, Carlos, El Cuerpo de oficiales en la guerra de España. Valladolid: AF Editores, 2008.

7. García Álvarez-Coque, op. cit.; García Álvarez-Coque, Arturo, "Los militares de Estado Mayor y su lealtad a la República (1936-1939)», Hispania Nova, n. ${ }^{\circ}$ 15, 2017.

8. Una parte de ellos (252) miembros del antiguo Cuerpo de EM, creado a principios del siglo XIX. El resto, oficiales diplomados de EM, con la misma cualificación profesional, mantenían la pertenencia a sus armas o cuerpos de origen. Se incluyen 62 oficiales alumnos de la Escuela Superior de Guerra. 
específicamente, dentro de este sector, un subgrupo de particular relevancia: los coroneles jefes de los Eemm 9 , la oficialidad más próxima a los generales al mando de las divisiones orgánicas. El jefe de un em tenía una función de asesor principal y correa de transmisión de las órdenes emanadas del general. En el contexto de la sublevación era potencialmente una pieza clave, por la influencia que pudiera tener sobre el mando superior para conseguir su adhesión al movimiento subversivo.

En julio de 1936 sólo se sublevaron tres de los doce generales de división con mando de tropas ${ }^{10}$, y sólo uno de los diez generales al mando de una división orgánica: el general Miguel Cabanellas en Zaragoza (contamos las ocho divisiones orgánicas peninsulares, la División de Caballería y las Fuerzas Armadas en Marruecos). ¿Cuál fue la actitud ante la sublevación de sus subordinados inmediatos, los coroneles jefes de los EEMm? Esta cuestión ha sido considerada tangencialmente por diversos autores ${ }^{11}$. Según la percepción transmitida en la bibliografía, las jefaturas de los EEMm tuvieron un protagonismo en la conspiración y la sublevación. Dichos jefes estarían en general afiliados a la ume (Unión Militar Española, organización clandestina radicalmente hostil al Frente Popular) ${ }^{12}$ y prácticamente en bloque se habrían adherido a la sublevación. En un apartado posterior presentaremos brevemente un estado de la cuestión.

Proponemos la hipótesis de que deben ser cuestionadas algunas conclusiones, o quizás ideas preconcebidas, sobre la actuación de las jefaturas de los EEMm. Actualmente se hallan disponibles fuentes de archivo que no eran fácilmente accesibles hace dos décadas. En el posicionamiento de estos jefes, como el de la oficialidad en general, pudo haber diversidad de matices. En el caso que consideramos, concurren al menos dos condicionantes. Uno de ellos, la proverbial lealtad al general jefe, propia de la función de EM. Esa relación de lealtad hacia el general era un eslabón especialmente resistente de la cadena de mando. Por otra parte, la circunstancia de muchos militares veteranos con el grado de coronel, no proclives a embarcarse en aventuras y con mucho que perder en caso de un fracaso.

9. Incluimos en este estudio las divisiones peninsulares y las fuerzas en Marruecos, pero no los еEмм de organismos no territoriales, como el Estado Mayor Central (García Álvarez-Coque, La fractura..., pp. 42-57).

10. Incluyendo a los generales Francisco Franco y Manuel Goded, al frente de las Comandancias Militares de Canarias y Baleares, respectivamente.

11. CARDONA, Gabriel, El poder militar en la España contemporánea hasta la guerra civil. Madrid: Siglo Xxi, 1983; CARDOnA, Gabriel, "El cataclismo de julio», en: La Guerra Civil, vol. 4, Historia 16, 1986; Busquets, Julio y Losada, Juan Carlos, Ruido de sables: las conspiraciones militares en la España del siglo Xx. Barcelona: Crítica, 2003; Gil Honduvilla, Joaquín, Militares y sublevación, Sevilla 1936. Brenes: Muñoz Moya-Editores Extremeños, 2011; Aróstegui, Julio, Por qué el 18 de julio... Y después. Barcelona: Flor del Viento, 2006; GuARner, Vicente, Cataluña en la guerra de España. Madrid: Gregorio del Toro, 1975.

12. Busquets y Losada, op. cit., p. 53; CARdona, Gabriel, El problema militar en España. Madrid: Ed. Historia 16, 1990 (2. ${ }^{\text {a }}$ ed. 2005, Alba Libros), p. 167. 


\section{Un estudio de Caso: los militares de Estado Mayor en la GUERRA CiVIL}

En conjunto, los militares de EM no fueron más o menos leales a la República que el resto de la oficialidad, aunque casos individuales son notorios en uno u otro sentido. Por ejemplo, el comandante de Em Bartolomé Barba, fundador de la ume, o el teniente coronel Valentín Galarza, enlace entre las tramas conspirativas civil y militar, llamado «el técnico» en el esquema golpista del general Emilio Mola ${ }^{13}$. Por razones diversas, no pocos militares de EM destacaron en ambos bandos. Por citar algunos: en las filas republicanas, José Asensio Torrado, Vicente Rojo, Leopoldo Menéndez, Vicente Guarner y Segismundo Casado; en las sublevadas, Manuel Goded, Joaquín Fanjul, Juan Vigón, Fidel Dávila, Antonio Aranda y Rafael García-Valiño.

El estudio sobre el EM proporciona estadísticas sobre la adscripción a uno u otro de los bandos en liza. En las primeras semanas de la guerra, en las que el factor geográfico fue especialmente determinante, un 23 por ciento de los militares de Em se hallaba al menos nominalmente en el campo gubernamental y un 36 por ciento con los sublevados. Un 3 por ciento había sido depurado por su oposición o falta de entusiasmo ante la sublevación (fusilado o dado de baja del ejército). A primera vista, una diferencia porcentual entre los dos bandos no demasiado grande. Sin embargo, el 35 por ciento restante, un grupo numeroso, eran militares desafectos al Gobierno que se hallaban en zona republicana (ocultos, encarcelados o fusilados), que en parte acabaron incorporándose a las filas franquistas (los «pasados» de la zona republicana a la sublevada) ${ }^{14}$. Otro dato muy ilustrativo: hacia el final de la contienda (ya desde aproximadamente finales de 1937) sólo un 12 por ciento de la oficialidad de em en activo en julio de 1936 se hallaba en el EPR, contra un 42 por ciento en el Ejército Nacional. El 46 por ciento restante para entonces ya no actuaba (muertos, encarcelados, ocultos o baja por diversas razones) ${ }^{15}$. Se ha argumentado que estas cifras de adscripción son una buena aproximación a lo ocurrido en el conjunto del Ejército, si consideramos sólo la oficialidad más determinante en el devenir de la guerra, los llamados armas y cuerpos combatientes (Infantería, Caballería, Artillería e Ingenieros) ${ }^{16}$.

Una relativamente pequeña minoría se mantuvo leal a la República durante toda la guerra, independientemente de que buena parte de estos «leales» no pensaran en una victoria militar sino en un pacto con los «compañeros» del ejército enemigo ${ }^{17}$.

13. Sobre la UME y el papel de la trama conspirativa civil monárquica, ViÑAs, Ángel, ¿Quién quiso la guerra civil?. Barcelona: Crítica, 2019; VIÑAs, Ángel, El gran error de la República. Barcelona: Crítica, 2021. También sobre la ume y las conspiraciones: Busquets y LosADA, op. cit., p. 53; GARCía RodríGuEz José, Conspiración para la Rebelión militar del 18 de julio de 1936. Madrid: Ed. Sylex, 2013.

14. García Álvarez-Coque, op. cit., pp. 123-127.

15. Ibídem, pp. 130-134.

16. Ibídem, pp. 133-134. Se ha propuesto que el método correcto para establecer las cifras de adscripción debe excluir las «armas y cuerpos no combatientes» (cuerpo Médico, Veterinaria, Farmacia, Intendencia, cuerpos jurídico y eclesiástico): Puell, "Julio 1936...», pp. 77-78; Alonso Baquer, Miguel, Franco y sus generales. Madrid: Taurus, 2005, pp. 43-47.

17. BAHAMONDE, Madrid 1939... 


\section{Las Jefaturas de los Eemm y El 18 de Julio: estado De la CUeStión}

Desde una perspectiva prosopográfica, en 1936 todos los jefes de los ЕEмм divisionarios se hallaban en la franja de edad de 46 a 59 años, ostentando el empleo de coronel (salvo el teniente coronel Tovar) ${ }^{18}$. Después del paso por la Academia de su arma habían ingresado en el Cuerpo de EM, una vez completados los cinco años de estudios y prácticas en la Escuela Superior de Guerra (ESG). Durante los años de esa etapa formativa, permeaba el mundo militar la visión de que la Patria y el Ejército se confundían entre sí, formando una triada con la Monarquía. En la etapa republicana, en algunos de estos militares pudo influir el nuevo concepto, encarnado por militares como el general Domingo Batet, para quien el Ejército no podía "atribuirse una representación [de la nación] que nadie le había dado» ${ }^{19}$. El caso del general Batet es doblemente paradigmático. Además de representar, con anterioridad al golpe de 1936, la idea cívico-republicana de nación, sufrió personalmente las consecuencias de ese posicionamiento: el 18 de julio fue destituido del mando de la Sexta División en Burgos y más tarde fusilado.

En la bibliografía aparecen afirmaciones sobre la actitud ante la sublevación de los jefes de Em, escalón directamente subordinado a los jefes divisionarios ${ }^{20}$. Como hemos señalado, salvo uno, los generales jefes divisionarios se mantuvieron leales. Por el contrario, se sublevó una mayoría de la oficialidad de nivel intermedio. ¿Fue así en el Cuerpo de EM? Este grupo, relativamente poco numeroso y cohesionado por el espíritu de cuerpo y por la naturaleza de su función, era un objetivo para el proselitismo de la ume. En la primavera de 1936 algunos oficiales de grado medio en los EEMM (comandantes o capitanes, el segmento de la oficialidad donde principalmente actuaba la UME) fueron captados para la conspiración. Sobre los jefes de Em Cardona apunta

en julio de 1936, la conspiración contaba con un solo mando de División Orgánica: Miguel Cabanellas, de Zaragoza. Pero había captado a casi todos los jefes de em que hacían un trabajo de zapa capaz de controlar la mayor parte de la organización ${ }^{21}$.

Para el mismo autor, la ume se convirtió en el «hilo comunicador» de la conspiración, que logró “captar hombres de todos los estados mayores» ${ }^{22}$.

18. Algunos datos personales y situación de cada uno, durante y al final de la guerra civil: GARCíA Alvarez-Coque, La fractura... pp. 223 y ss.

19. Velasco-Martínez, Luis, La Nación Marcial, tesis doctoral, Universidad de Santiago de Compostela, 2020, pp. 268, 353, 357.

20. Por ejemplo, Cardona, El poder militar..., pp. 155, 306-307; CARdona, "El cataclismo...», pp. 26-30; Busquets y losada, op. cit., p. 53; Gil Honduvilla, op. cit., p. 94; Aróstegui, op. cit., pp. 77, 79; GuARnER, op. cit., p. 135.

21. CARDOna, "El cataclismo...", p. 26

22. CARDONA, El problema militar..., p. 167. 
Según Busquets, «de los nueve coroneles jefes de los estados mayores divisionarios $^{23}[\ldots]$ siete se sublevaron, cinco de los cuales pertenecían, con toda certeza, a la ume: Cantero, jefe de Estado Mayor de Sevilla, Moxó de Barcelona; Montaner de Zaragoza; Moreno Calderón de Burgos, y Ungría, del Estado Mayor de la División de Caballería» y, añade este autor, «ignorándose si pertenecían o no a la ume los dos coroneles sublevados restantes: Quero, de Valladolid y Tovar, de La Coruña» ${ }^{24}$.

Conviene aclarar que "perteneciente a la UME» no equivale a "conspirador». Para muchos la ume era sólo una organización de defensa de intereses corporativos. La afiliación a ella no significaba necesariamente una identificación con el golpismo ni con posturas ideológicas reaccionarias ${ }^{25}$.

En los relatos sobre lo ocurrido en cada territorio entre el 17 y el 20 de julio de 1936, a menudo aparecen como protagonistas los jefes de EM. Se ha resaltado el papel del coronel Fernando Moreno Calderón, del em del general Domingo Batet en Burgos: "son los militares que rodean a Batet los mismos que encabezan la rebelión dirigidos por Moreno Calderón», apunta Aróstegui ${ }^{26}$. Cardona afirma que, aunque Mola había dado su palabra de honor a Batet de no sublevarse, «su propio jefe de EM coronel Moreno Calderón era un hombre de Mola» ${ }^{27}$.

En Valladolid, el protagonismo fue del EM, según afirma Guarner, que dice so-

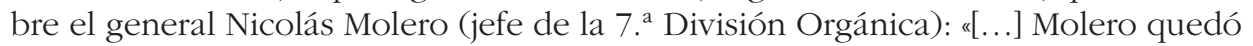
malherido al resistir a su Estado Mayor, levantado en $\operatorname{armas}^{28}$.

Asimismo, varios autores han visto en el teniente coronel Luis Tovar (jefe de EM en la Octava División, con cabecera en La Coruña) un protagonista principal en la sublevación ${ }^{29}$.

Las sumarios relativos a los consejos de guerra contra generales opuestos a la sublevación, como Batet, Salcedo y Molero (fusilados los dos primeros), contienen una riqueza documental que permite dilucidar el comportamiento de los EEMM en cada caso. Las causas judiciales contra los propios jefes de EM y otras fuentes

23. Busquets no contabiliza aquí a la jefatura de las Fuerzas Armadas de Marruecos.

24. Busquets y losada, op. cit., p. 53; Cardona, El problema militar..., p. 167.

25. González Calleja, Eduardo. Contrarrevolucionarios, Madrid: Alianza Editorial, 2011, pp. 292, 341.

26. Aróstegui, op. cit., p. 79.

27. CARDONA "El cataclismo...", p. 28.

28. GuARner, op. cit., p. 135.

29. Según Aróstegui, op. cit., p. 77, "se produjo un rápido movimiento de la División, dirigido por el jefe del Em, teniente coronel Luis Tovar, tras el que es detenido el general Salcedo. Una vez más, un jefe de em de una División toma la iniciativa de los sublevados» (Aróstegui se refiere a que en Burgos el coronel Moreno Calderón tomó la iniciativa de los sublevados). Según ALÍA, Francisco, Julio de 1936. Conspiración y Alzamiento contra la Segunda República. Barcelona: Crítica, 2011, p. 91, que se basa en De JuAnA, Jesús y PRADA, Julio, Lo que han hecho en Galicia. Violencia, represión y exilio (1936-1939), Barcelona: Crítica, 2006, p. 102, Tovar «dirigió la conspiración en su última fase» y era «representante regional de la ume». Según Cardona, op. cit., p. 30, "No estaba sólo (el coronel Martín Alonso) en la conspiración gallega. El jefe de Em de la División, coronel Tovar, ya bastante tiempo atrás era secretario regional de la UME». 
archivísticas o bibliográficas permiten asimismo esclarecer lo ocurrido en otros territorios: Madrid, Sevilla, Valencia, Barcelona y el Protectorado de Marruecos.

\section{LA CONSPIRACIÓN Y LA SUBLEVACIÓN EN LOS EEMM DIVISIONARIOS}

Las actitudes en el grupo de jefes de EM respecto a la conspiración dirigida por el general Mola, y a la sublevación de julio de 1936, son sintetizadas en el cuadro siguiente, correspondiente a las diez divisiones peninsulares, más las Fuerzas en Marruecos. En el resto del artículo desarrollaremos detalles de lo ocurrido en cada división, a fin de explicar estas conclusiones ${ }^{30}$.

\section{CUADro 1}

LOS JEFES DE EM DIVISIONARIOS EN LA CONSPIRACIÓN Y LA SUBLEVACIÓN

\begin{tabular}{|c|c|c|c|}
\hline DiVISIÓN & JEFE DE EM & $\begin{array}{c}\text { CONSPIRADOR } \\
\text { (1) }\end{array}$ & $\begin{array}{l}\text { SUBLEVADO } \\
\text { (2) }\end{array}$ \\
\hline Primera (Madrid) & Luis Pérez-Peñamaría Vélez & $\mathrm{X}$ & \\
\hline Segunda (Sevilla) & Juan Cantero Ortega & & \\
\hline Tercera (Valencia) & Adolfo Machinandiarena Berga & & \\
\hline Cuarta (Barcelona) & Manuel Moxó Marcaida & $\mathrm{X}$ & $\mathrm{X}$ \\
\hline Quinta (Zaragoza) & Federico Montaner Canet & $\mathrm{X}$ & $\mathrm{X}$ \\
\hline Sexta (Burgos) & Fernando Moreno Calderón & & $\mathrm{X}$ \\
\hline Séptima (Valladolid) & Juan Quero Orozco & & $\mathrm{X}$ \\
\hline Octava (La Coruña) & Luis Tovar Figueras & & $\mathrm{X}$ \\
\hline División de Caballería & José Ungría Jiménez & $\mathrm{X}$ & $\mathrm{X}$ \\
\hline Jefatura Superior Marruecos & Francisco Martín Moreno & & $\mathrm{X}$ \\
\hline TOTAL & 10 & 4 & 7 \\
\hline
\end{tabular}

(1) conspirador: formaba parte del núcleo conspirativo, enlazado con el plan del general Mola.

(2) sublevado puede referirse $a$ :

- sublevados proactivos, comprometidos con la conspiración (Montaner, Moxó).

- no comprometidos con la conspiración pero actuaron a favor de la sublevación (Moreno Calderón) o se sumaron a ella cuando ya había triunfado (Quero).

30. Los pormenores sobre la conspiración y sublevación en cada una de las divisiones: García Álvarez-Coque, op. cit., pp. 21-108. También, Alía, op. cit., Aróstegui, op. cit., Gil Honduvilla, op. cit.; SALAS, op. cit. 


\subsection{Primera División: El fracaso en Madrid y el coronel Peñamaría}

El jefe de em de la División, coronel Luis Pérez-Peñamaría ${ }^{31}$, participó en reuniones preparatorias del movimiento militar en Madrid, cuyo coordinador era el teniente coronel de Ingenieros Alberto Álvarez Rementería (delegado de la UME) y que encabezaban nominalmente los generales Villegas, Fanjul y, designado a última hora, el general García de la Herrán. En una tónica general de improvisación, a Peñamaría no le fue asignado ningún papel específico, más allá de permanecer en su puesto en el EM. Sin embargo, a primeros de julio, Mola le encargó sondear la actitud del general Miaja, máxima autoridad con mando efectivo de tropas en Madrid. Según el sumario contra Peñamaria (procesado en 1939 por supuesta negligencia al no apoyar la sublevación), esas gestiones de acercamiento a Miaja se toparon con la actitud negativa o al menos ambigua del general. Peñamaría participó incluso en una reunión en la tarde del 17 de julio, en la que comunicó el resultado negativo de la gestión que Mola le había encomendado para sondear a Miaja. En esa misma reunión fue presentado el general Miguel García de la Herrán, llamado (al parecer el día 16) a incorporarse a la dirección de la sublevación en Madrid $^{32}$. Peñamaría no dice si en la reunión la tarde del día 17 con las cabezas del movimiento (Rementería y García de la Herrán) se concretó algún plan de acción. Esa reunión tenía lugar aproximadamente al mismo tiempo que el inicio del levantamiento en Melilla.

Entre el 18 y el 20 de julio, con algunas unidades en Madrid abiertamente sublevadas, el coronel Peñamaría, desde su puesto en el Palacio de los Consejos (sede de la Primera División Orgánica), continuó cumpliendo su papel como jefe de EM, acatando y transmitiendo las órdenes de los generales nombrados por el Gobierno que se sucedieron al frente de la División. Su connivencia con los sublevados no llegó nunca a traducirse en acción, ante unas circunstancias cada vez más desfavorables para los rebeldes.

Peñamaría fue sometido a consejo de guerra tanto por los republicanos como, más tarde, por los franquistas. Por parte de los gubernamentales, las sospechas contra el coronel eran sobre una supuesta obstrucción a las órdenes del ministro para armar a las milicias el día 19, y al traslado de un obús del 15,5 a la Plaza de España para el asedio al sublevado Cuartel de la Montaña. Sólo se mantuvo la segunda acusación: haber conminado y rogado al teniente coronel Rodrigo Gil, jefe del Parque de Artillería, que no enviase la pieza del 15,5 para atacar el Cuartel. A favor de Peñamaría fue decisiva la declaración del propio Rodrigo Gil. Peñamaría se había limitado a obedecer órdenes de su general (en ese momento el general

31. Archivo General Histórico de Defensa (Madrid) [AGHD], sum. 2273 contra Luis Pérez-Peñamaría Vélez, f. 3.

32. García Venero, Maximiano, Madrid, Julio 1936. Madrid: Ediciones Tebas, 1973, pp. 307-311; sum. 2273, op. cit., f. 3. La reunión fue celebrada en el n. ${ }^{\circ} 16$ de la calle de Fernán González, casa de Román Álvarez Omaña, sobrino y pasante del político republicano conservador Melquíades Álvarez. 
García Antúnez). Por tanto el Tribunal Popular pronunció una sentencia absolutoria el 8 de noviembre de 1936. El coronel se comprometió a prestar sus servicios a la República dondequiera se le confiriese destino o mando. Sin embargo, el coronel ingresó en la Legación de Suecia el mismo día en que terminó el juicio.

La absolución de Peñamaría por el tribunal rojo (a pesar de su supuesta actuación a favor de la sublevación) fue justificada ante los jueces franquistas por las argucias legales de su abogado defensor, que al parecer colaboraba con la quinta columna y que organizó el ingreso del coronel en una Legación diplomática. En marzo de 1938 se evadió de la Legación y permaneció oculto, colaborando con la organización militar de Falange en Madrid en los últimos meses de la guerra.

Peñamaría fue procesado en abril de 1939 por su tibieza a favor de la sublevación, compareciendo ante un consejo de guerra por delito de negligencia. Las declaraciones de testigos presentes los días de los hechos fueron favorables al coronel. Alguna de ellas, como la del comandante de em Juan Cisneros, una verdadera disertación teórica sobre doctrina militar explicando porqué Peñamaría actuó correctamente como jefe de EM, en vista de la carencia de instrucciones ${ }^{33}$. Tanto el coronel como algunos otros testigos sostuvieron que en realidad se hallaban sublevados (aunque ello al parecer no era evidente para las autoridades gubernamentales...). En el consejo de guerra el fallo fue condenatorio a seis meses y un día por delito de negligencia, con voto particular de tres vocales en favor de la absolución, pero con disentimiento del Auditor que pidió tres años y un día.

El coronel Peñamaría es visto como «el jefe más caracterizado en aquellos momentos» y podía incluso ser percibido como la tercera autoridad militar en Madrid, después del ministro y del general jefe de la División. En realidad, como buen jefe de EM, el coronel actuó en acatamiento estricto de las órdenes de sus superiores. En sus declaraciones ante el juez franquista, el coronel omitió mencionar su presentación ante el nuevo ministro rojo Luis Castelló cuando este entró en funciones el 19 de julio.

Finalmente el Consejo Supremo de Justicia Militar confirmó en mayo de 1941 la pena de seis meses y un día, con la accesoria de suspensión de empleo. La sentencia final considera que si bien su conducta no podía considerarse rebelión militar, sí aprecia negligencia pues

existía un mando superior obligado a dictar las órdenes precisas, al no hacerlo por motivos u obstáculos cuyo esclarecimiento no es preciso ni adecuado en el actual momento, el Coronel que nos ocupa debió suplirlo, haciendo frente a la vergüenza y oprobio que representaba el populacho desmandado por las calles de Madrid [... $]^{34}$.

Aunque la accesoria de suspensión de empleo prevé la reintegración en el servicio una vez cumplida la pena, el coronel Luis Pérez-Peñamaría causó baja

33. Sum. 2273, op. cit., f. 45.

34. Ibidem, f. 87. 
definitiva en el Ejército en noviembre de 1941, en aplicación de la Ley Varela de retiros forzosos.

\subsection{Segunda División:El EM de Sevilla y el golpe de Queipo de Llano}

El comandante José Cuesta Monereo, con algunos de sus compañeros en el EM en Sevilla, diseñó y ejecutó un plan que culminó con el éxito del golpe del general Queipo de Llano, exageradamente atribuido a la audacia de Queipo en publicaciones hagiográficas. El comandante Cuesta estableció un EM paralelo que preparó y en gran medida ejecutó el golpe de mano que dio a Queipo posesión del mando de la División, en sustitución del general José Fernández de Villa-Abrille Calivara ${ }^{35}$.

Mientras tanto, el coronel Juan Cantero Ortega, jefe del Em en Sevilla, se encontraba con permiso de verano en Algeciras. No demostró entusiasmo por la sublevación y no se presentó en su destino en el Cuartel General en Sevilla hasta el 8 de agosto. Fue retirado del Ejército por su tardía presentación. Un oficio «Muy reservado» en el expediente de Cantero

Dispuesto por Decreto fecha 23 del actual, pase a la situación de retirado el Coronel de em D. Juan Cantero Ortega [...] el motivo fundamental [...] ha sido su tibieza y falta de espíritu al no incorporarse a la División de que era Jefe de Estado Mayor en circunstancias graves para la Patria, así como por su falta de condiciones para el mando... Burgos, 26 de diciembre de 1936,... El General Jefe ${ }^{36}$.

\subsection{Tercera División: La no sublevación en Valencia}

El propio jefe de la ume, comandante Bartolomé Barba, era el jefe honorífico de la junta que preparaba la rebelión en Valencia. Barba era natural de la capital levantina y se hallaba entonces en situación de supernumerario sin sueldo. En las semanas previas al 18 de julio, este comandante se implicó más en enlazar con elementos civiles (Derecha Regional Valenciana, Falange, Tradicionalistas) que en preparar un movimiento militar ${ }^{37}$.

Uno de los hechos que ilustran mejor las lagunas e improvisaciones en el golpe militar de 1936 es la indeterminación que surgió, a fecha 16 de julio, sobre quien encabezaría la sublevación en Valencia, por el cambio que asignó el mando en Barcelona al general Goded, en lugar de quien estaba previsto que actuara en

35. Gil Honduvilla, op. cit., p. 199.

36. Archivo General Militar de Segovia [AGMS], expediente de Juan Cantero Ortega, C-1014. Un hermano de Cantero, el coronel José Cantero, estaba al mando de la guarnición de Badajoz y fue fusilado el 14 de agosto, al entrar las tropas sublevadas en esa ciudad.

37. Sobre la sublevación en Valencia: Archivo Histórico Nacional [AHN], Pieza segunda de Valencia, Del Alzamiento Nacional, FC-Causa General, 1389, 1; AGHD, sum 271-V, Manuel González Carrasco (causa abierta contra el general Carrasco por el fracaso en Valencia). 
la capital catalana, el general Manuel González Carrasco. Según el plan de Mola hasta entonces, Goded debía sublevar Valencia.

Contrariamente a Barcelona y Madrid, en donde el desenlace de la rebelión se decidió prácticamente en un día, en Valencia persistió una situación de desconcierto y ambigüedad durante casi dos semanas. La oficialidad favorable al alzamiento no pudo dar el paso definitivo al no lograr la adhesión del jefe de la División general Fernando Martínez Monge, y por la decidida oposición de jefes como el coronel Jesús Velasco y el comandante Joaquín Pérez-Salas, del Regimiento de Infantería Otumba n. ${ }^{\circ} 9$ y del Regimiento de Artillería Ligera n. ${ }^{\circ} 5$, respectivamente.

Una razón para la escasa implicación de la oficialidad del em de la Tercera División en la preparación del alzamiento fue el no haber contado con el jefe del EM coronel Adolfo Machinandiarena, considerado elemento poco fiable, leal a Martínez Monge. Según el capitán de em José Soto Serra.

al E.M. de la División no se le tenía informado de la preparación del Movimiento, ni de los actos que se preparaban, ni se le dio misión de ninguna clase, manteniéndole por completo alejado de todo ello, dijo el comandante Barba al declarante, para no crearles una situación difícil con el general de la División ${ }^{38}$.

Lo dicho sobre mantenerles al margen "para no crearles una situación difícil con el general de la División» se refiere al conflicto en algunos oficiales entre guardar el secreto de la conspiración y el deber de lealtad, esencia de la función de em.

Todos los oficiales del EM de Valencia sirvieron en el Ejército Popular en grados diversos aunque con escaso entusiasmo, y fueron procesados durante o al final de la guerra. El coronel Machinandiarena fue trasladado a Madrid en agosto de 1936, al parecer por el temor sobre la seguridad de los militares profesionales en Valencia. El coronel se ocultó, pero fue encarcelado. Se evadió en noviembre de 1937 a la zona franquista, donde fue procesado por no sumarse al Alzamiento Nacional, en particular por haber informado al general de la División el 17 de julio sobre la inminencia de la sublevación ${ }^{39}$. La declaración de un testigo contra Machinandiarena habla de "su mal entendida lealtad»:

hubiera secundado el Movimiento Nacional si el general Martínez Monje así lo hubiera hecho, pero me parece no hizo nada para que triunfase el Movimiento..., antes bien con su mal entendida lealtad al mando se identificó mucho con el general no haciendo nada para convencer a éste que evitase los actos de barbarie que se realizaron en Valencia ${ }^{40}$.

Fueron desmesuradas las declaraciones del testigo comandante Bartolomé Barba que, en su afán de descargar culpas sobre otros, lanzó graves acusaciones

38. AGHD, Declaración José Soto Serra, sum. 271-V, op. cit., f. 313.

39. Archivo Intermedio Militar del Noroeste, El Ferrol [AImnor], Fondo Valladolid, causa 219, Adolfo Machinandiarena Berga.

40. Ibidem, declaración capitán de Ingenieros Pascual Silla, f. 94. 
contra el coronel, según él uno de los principales culpables del fracaso, así como de propiciar la detención y fusilamiento de miembros de la junta de Valencia y de colaborar en la salida de tropas para luchar contra los sublevados. Machinandiarena fue condenado a seis años y un día y separado del servicio.

\subsection{Cuarta División: El fiasco de Barcelona}

En la junta que preparó el alzamiento en Cataluña, el comandante Francisco Mut era el activo representante de los conspiradores en el EM de la Cuarta División. Era el enlace con Mola en Pamplona y con Goded en Mallorca. Mut seguramente mantenía informado a su jefe el coronel Manuel Moxó, quien conocería sus desplazamientos conspirativos.

La preparación del alzamiento en Barcelona ${ }^{41}$ contó con la plena complicidad del em de la Cuarta División, que se mantuvo enlazado con Mola y con el general Manuel Goded, quien a última hora asumió el mando de la sublevación en la capital catalana. El EM, con su jefe el coronel Manuel Moxó, estaba «influido» por la trama golpista, según el entonces Jefe de Orden Público, comandante Vicente Guarner y su superior, el capitán Frederic Escofet, Comisario de Orden Público de la Generalitat. Días antes habían tenido conocimiento del plan golpista y preparado una respuesta armada en las calles de Barcelona. Escofet refiere que documentos recogidos a los conspiradores tenían el sello del EM, que según el coronel Moxó no era auténtico. Escofet dice de Moxó: «demostró ser el más vil de los traidores» ${ }^{42}$.

Cuando el general Goded se presentó procedente de Palma de Mallorca, hacía ya más de siete horas que la rebelión había empezado y habían sido prácticamente neutralizadas las tropas sublevadas, que se lanzaron a las calles de la ciudad infravalorando a las fuerzas que les iba a oponer el Gobierno.

La mañana del 19, mientras los sublevados intentaban avanzar por las calles de Barcelona, en el Cuartel General de la División se vivía una situación extraña. Mientras que el EM estaba en connivencia con los sublevados, su superior, el jefe de la Cuarta División general Francisco Llano de la Encomienda, leal al Gobierno, se mantuvo en su puesto ejerciendo el mando. En el informe del general Llano sobre lo acaecido el día 19, con motivo del proceso contra los generales Goded y Fernández Burriel, el general afirma que su jefe de em Manuel Moxó se mantenía a sus órdenes. Dice en su informe: "Las órdenes contra los sublevados a veces las transmitía el jefe de EM, otras veces él (Llano) por el hilo directo con los cuarteles y la Consejería» ${ }^{43}$. Al presentarse el general Goded, llegado desde Palma para

41. Sobre la sublevación en Barcelona, Romero, Luis, Tres dias de julio. Barcelona: Plaza \& Janés, 1987, pp. 263-306; GuARner, op. cit., pp. 89-132; Escofet, Federico, De una derrota a una victoria: 6 de octubre de 1934-19 de julio de1936. Barcelona: Argos Vergara, 1984, pp. 225-327; MERINO, Jacint, Los militares se sublevan en Barcelona. Barcelona: Ed. Base, 2013.

42. ESCOFET, op. cit., pp. 226-227.

43. AHN, FC-Causa General, 1537, 2, f. 252. 
encabezar la sublevación, el EM y su jefe Moxó se pusieron a sus órdenes. Dice el comandante Carlos Lázaro, ayudante del general:

Burriel hizo entrega del mando al general Goded, teniendo este unas palabras violentas con el que fue general Llano de la Encomienda, que en aquellos momentos aún se encontraba en su despacho oficial con su jefe de EM coronel Moxó, quien al ver al general Goded se puso inmediatamente a sus órdenes ${ }^{44}$.

Según su declaración, una vez prisionero junto a sus dos ayudantes y su hijo, el general Llano pudo presenciar:

la constante entrada y salida de casi todo el que había sido mi Estado Mayor, que dirigiéndose de un despacho a otro comunicaba las órdenes del general Goded, las frases del Jefe del Estado Mayor que dirigiéndose a mí me dijo por dos veces: «¿Me perdonas, mi general?», a las que le contesté que nunca, y el verme traicionado y reducido me produjo una excitación nerviosa que les obligó a llevarme a mi habitación particular ${ }^{45}$.

Según este testimonio sobre un coronel Moxó pidiendo perdón a Llano, la traición a su jefe habría producido un choque moral al jefe del EM. Hasta ese día el general Llano no había dudado de la lealtad de Moxó, quien había permanecido junto a él en su despacho la víspera, en la noche del 18, "por si surgía alguna novedad" 46 .

En la tarde del 19 se rindió Capitanía y fueron hechos prisioneros Goded, Burriel y el EM. El coronel Moxo fue fusilado en una saca del buque prisión Uruguay, el 20 de agosto de $1936^{47}$.

\subsection{Quinta División: "El general más republicano»}

En las instancias gubernamentales no se dudaba de la lealtad de Miguel Cabanellas, considerado uno de los generales más adictos a la República. Adherido a la masonería, con anterioridad a 1936 Cabanellas había hecho gala de su republicanismo $^{48}$, pero su deriva anti-Frente Popular, no valorada por el Gobierno, culminó en su adhesión al plan de Mola y a la idea de una "dictadura republicana» ${ }^{49}$.

44. AHN, «Declaración de testigo de Carlos Lázaro Muñoz», FC-Causa General, 1513, 18, f. 12.

45. Parte del general Llano de la Encomienda sobre los hechos acaecidos el 19 de julio: AHN, FC-Causa General, 1537, 2, f. 254.

46. Ibídem, f. 249. Sobre los "problemas de conciencia» de Moxó, el Comisario Escofet refiere que el coronel Moxó, prisionero en la División, se acercó queriendo justificarse por haberle mentido al teléfono asegurando que el general Goded no se encontraba en la División (había sido obligado a ello por Goded, que se encontraba a su lado: Escofet, op. cit., p. 325).

47. Los generales Goded y Fernández Burriel fueron juzgados en consejo de guerra y fusilados.

48. Por ejemplo, el relato de Vicente Guarner sobre la exigencia de Cabanellas, entonces Inspector General del Ejército, de colocar en las dependencias militares grabados alegóricos de la República (GuARnER, op. cit., p. 51-52).

49. Cardona, El poder militar,... p. 242; González Calleja, op. cit. pp. 349-350. 
El coronel Federico Montaner, jefe de em de la División, independientemente de su grado de afinidad con el Movimiento Nacional, en principio no hizo más que permanecer en su puesto, secundando al general Cabanellas, su mando natural. La mayor parte del em de la División estaba preparado para secundar la sublevación, a pesar de ser época de permisos de verano. No nos extenderemos en este apartado pues en Zaragoza no existió un golpe militar en tanto que acción necesaria para dominar la cabecera de la División.

\subsection{Sexta División: La resistencia del general Batet}

El coronel Fernando Moreno Calderón había sido destinado a Burgos como jefe de em del general Domingo Batet Mestre, incorporándose el 8 de julio, pocos días antes del movimiento militar. Pero el coronel no conoció hasta la misma tarde del 18 de julio el movimiento que iba a estallar contra el Gobierno de Madrid ${ }^{50}$. El general Mola no tenía preocupaciones con la Sexta División, pues además de contar con el EM (mandado interinamente por su amigo el teniente coronel José Aizpuru hasta la llegada de Moreno Calderón), contaba con su homólogo con mando de tropas en Burgos, el general de brigada Gonzalo González de Lara. Los planes se torcieron a última hora pues las autoridades republicanas, conociendo la actividad conspirativa de González de Lara, le detuvieron el día 16, junto con otros conjurados. Esta situación imprevista fue resuelta a favor de los sublevados en la noche del 18 al 19, por la acción del Estado Mayor, a su vez bajo la presión de la guarnición de Burgos, de hecho ya sublevada.

En el anterior apartado sobre el «estado de la cuestión» ya hemos señalado cómo Moreno Calderón ha sido citado como cabeza de la rebelión contra Batet, y calificado incluso como un "hombre de Mola" ${ }^{51}$. La idea de que fue el jefe de EM quien dirigió la sublevación debe ser desmentida o matizada. El coronel no era parte del núcleo conspirativo, aunque ocasionalmente hubiese participado en reuniones de oficiales hostiles al Gobierno en su anterior destino en la Escuela Superior de Guerra. No fue hasta la tarde del mismo día 18 que Moreno Calderón tuvo conocimiento (por el teniente coronel Aizpuru, este sí un hombre de Mola) de que había un movimiento en marcha en la guarnición. Su primera reacción fue informar al general: "En el acto subió a ver al general Batet al cual puso en antecedentes, expresándole su particular opinión de que el sentir de la guarnición de Burgos era tan hondo que no habría medio de impedirlo» 52 . A pesar de su afinidad con los alzados, el jefe del EM mantuvo hasta el último momento estricta obediencia a su jefe el general Batet. Ante la inevitabilidad del alzamiento, el coronel y sus oficiales intentaron convencer al general para que se pusiera a la cabeza del mismo

50. Aimnor, Fondo Burgos, causa 130-36, Domingo Batet Mestre, f. 51-V; Aimnor, causa 991-38, Fernando Moreno Calderón, f. 3.

51. Aróstegui, op. cit., p. 79; Cardona, op. cit., p. 28.

52. Causa 991-38, op. cit, ff. 3-3V. 
con toda la Sexta División, difícil tarea en vista de los antecedentes de Batet como militar respetuoso de la legalidad y orgulloso de su Cruz Laureada ganada defendiendo el orden constitucional en Barcelona en octubre de 1934.

Ante el ultimátum del coronel Gistau del Regimiento de Infantería San Marcial (el principal cuerpo armado en la capital burgalesa), quien amenazaba con tomar la División por la fuerza, y dada la actitud irreductible de Batet, el grupo de EM procedió a la detención del general sobre las tres de la madrugada del 19, en una escena en que se hallaban presentes el conspirador Aizpuru y oficiales más jóvenes del Em. Como Batet seguía negándose en absoluto a tomar el mando a favor de la rebelión, dice en su declaración Moreno Calderón: «Entonces el declarante le dijo, "mi general, queda usted detenido", en cuyo momento el comandante Algar le puso, con toda corrección, la mano en el hombro" ${ }^{33}$. El general Domingo Batet sería procesado por adhesión a la rebelión y fusilado en febrero de 1937.

La actuación de Moreno Calderón fue considerada por algunos como ambigua, al grado de que en junio de 1938 le fueron instruidas diligencias previas, en las que se llegó a poner en cuestión su actitud personal de adhesión al Movimiento, finalmente resueltas a su favor sin responsabilidad ${ }^{54}$. Para el coronel, Batet fue su jefe hasta el final, mientras que para la mayor parte de la oficialidad el general era un obstáculo para lograr sus fines. Sin duda el coronel se adhirió a la sublevación, pero se resistió hasta el último momento a la destitución de Batet, la que quizás creyó poder evitar a través de alguna negociación. Hubo idas y venidas del coronel entre la División y el Cuartel de Infantería, como emisario de las órdenes del general. En la reunión de jefes de cuerpo en el Cuartel, el coronel advirtió a los oficiales sublevados:

Señores, estoy con vosotros en todo y para todo. Ahora que, como oficial de Estado Mayor, no tengo más remedio que transmitir a ustedes las órdenes de mi superior, que es el general Batet.

Según un testigo, Moreno Calderón también pronunció la frase:

El Estado Mayor tiene que hacer de enlace entre el Mando y las tropas [...] mientras haya un átomo de vida en el Mando, el Estado Mayor tiene que estar con éste ${ }^{55}$.

El hombre fuerte entre los sublevados de Burgos era José Gistau, el coronel del San Marcial, que declaró: «el coronel Moreno Calderón siguió desempeñando sus funciones con incansable actividad y la mayor lealtad al Movimiento ${ }^{56}$. Según la hoja de servicios del coronel «por telegrama de 20 de julio fue nombrado por el general D. Emilio Mola Vidal desde Pamplona Jefe de Estado Mayor del General

53. Ibídem, f. 3V. Sobre la detención de Batet, causa 130-36 op. cit., f. 35V.

54. Causa 991-38 op. cit.

55. Ibidem, f. 7.

56. Ibidem, f. $14 \mathrm{~V}$. 
Sanjurjo, que había de ponerse al frente del Movimienton ${ }^{57}$. Fallecido Sanjurjo, el coronel quedó a las órdenes de Mola. La hoja de servicios relata la constitución del primer gobierno de la España sublevada, la "Junta de Burgos», constituida por el general Miguel Cabanellas como Presidente, y vocales los generales de brigada Mola, Saliquet, Dávila y Ponte y los coroneles de Estado Mayor Montaner y Moreno Calderón.

\subsection{Séptima y Octava Divisiones: Triunfo en Valladolid y La Coruña}

\section{Séptima División (Valladolid)}

En Valladolid el golpe se consumó hacia las 23 horas del 18 de julio cuando el jefe de la Séptima División, general Nicolás Molero Lobo, fue violentamente destituido por un grupo de generales, jefes y oficiales sublevados, resultando muertos en un tiroteo los dos ayudantes del general y un civil, además de herido el mismo general Molero. Además de la bibliografía general citada en el apartado 4, para el relato siguiente utilizamos la causa abierta contra el general Molero por no unirse a la sublevación ${ }^{58}$. Valladolid es otro caso más en que según comentaristas y autores, el protagonismo fue del Em. Ya hemos citado la afirmación de Vicente Guarner: «el general Molero [...] quedó malherido al resistir a su Estado Mayor, levantado en armas " 59 . En realidad, el EM de la División no intervino de ninguna forma en el golpe en la capital vallisoletana, primera plaza en la Península donde el movimiento militar triunfó. La toma del control de la División fue obra de un grupo de militares desplazados desde Madrid (por tanto ajenos a la División) bajo el mando del general Andrés Saliquet Zumeta, que se encontraba en activo aunque en situación de disponible. Este grupo estaba compuesto por jefes y oficiales del sector más antirrepublicano del Ejército. Además del general Saliquet y del aristócrata y conspicuo conspirador general Miguel Ponte y Manso de Zúñiga, componían el grupo tres militares del Cuerpo de EM: el teniente coronel Enrique Uzquiano Leonard y los comandantes Anselmo López Maristany y Luis Martín-Montalvo Gurrea ${ }^{60}$.

El día 18 hacia las 22:30 horas el grupo penetró en el edificio de la antigua Capitanía. Saliquet y Ponte se entrevistaron con un general Molero sorprendido ante la intempestiva vista, para persuadirle de encabezar el movimiento o ceder el mando. Como resultado del tiroteo que siguió murieron el ayudante de Molero, comandante Ruperto Riobóo, el también ayudante comandante Ángel Liberal y el

57. agms, hoja de servicios de Fernando Moreno Calderón, CAJA 829, EXP 7.

58. Aimnor, Fondo Valladolid, causa 37-37, Nicolás Molero Lobo. También la obra coetánea Raymundo, Francisco, Cómo se inició en Valladolid el Glorioso Movimiento Nacional y la Gesta beroica del Alto del León, Valladolid: Imp. Católica, 1936.

59. Guarner, op. cit., p. 135.

60. Causa 37-37, op.cit., f. 80; AGms, hojas de servicio de Enrique Uzquiano Leonard y Anselmo López Maristany. La hoja de servicios del comandante Martín-Montalvo no se ha localizado. 
miliciano de Renovación Española Emeterio Estefanía, y resultaron heridos levemente el general Molero y Uzquiano. Con el general Saliquet al mando, el estado de guerra en Valladolid fue declarado hacia las dos de la madrugada ${ }^{61}$.

¿Qué papel tuvo el EM de Valladolid en el golpe?. Ninguno. No participaba ningún miembro del em en la junta conspiradora local, aparte de López Maristany mientras estuvo destinado en Valladolid, hasta el mes de mayo. En el momento de la llegada del grupo encabezado por Saliquet, el coronel jefe del em Juan Quero Orozco se encontraba en su domicilio en un pabellón anexo a la División. Fue requerido por teléfono para que bajase al despacho del general Molero. Encontró a los tres generales conversando y la entrevista parecía había terminado. El coronel Quero salía del despacho con el resto del grupo, en actitud de despedida, cuando el general Molero le ordenó "Pida comunicación telefónica y llame a Madrid», y aunque nada añadió Quero supuso que sería al Ministerio de la Guerra. Mientras el grupo salía a la galería el coronel Quero permaneció encerrado en el despacho intentando establecer la comunicación. Pocos instantes después Quero escuchó los disparos, pensando que provenían de la calle y se asomó al balcón. Salió del despacho, encontrando una escena en la que había muertos y heridos ${ }^{62}$. El jefe del EM había sido sorprendido por el movimiento, siendo un mero espectador. Una vez asumido el mando por Saliquet, Juan Quero se sumó a los alzados. En su hoja de servicios consta simplemente: «El 18 de julio al estallar en Valladolid el Glorioso Movimiento Nacional, se adhirió a él desde el primer momento».

La Octava División (La Coruña). Los últimos en sublevarse

En La Coruña, el 20 de julio la oficialidad de la Octava División se unió a la sublevación destituyendo a los mandos superiores, generales Enrique Salcedo Molinuevo y Rogelio Caridad Pita. El principal apoyo de Mola era Pablo Martín Alonso, antiguo africanista procesado por la Sanjurjada, coronel del Regimiento de Infantería y por tanto quien ostentaba el mando directo de tropas en La Coruña. Martín Alonso estaba a las órdenes del general Caridad Pita, hasta la detención de este por los golpistas.

Como jefe de Em, el teniente coronel Luis Tovar Figueras mantenía (al menos formal y exteriormente) estricta lealtad a su general. En sus declaraciones en el proceso contra el general Salcedo, Tovar no da indicaciones de que conspirara de ninguna manera, sólo menciona que recibía «noticias e impresiones por compañeros» de que se proyectaba un movimiento militar. Algunos autores han visto en el teniente coronel Tovar (como en otros jefes de EM) un protagonismo mayor del que realmente tuvo, calificándole de «director de la conspiración en su última fase», asociado con el conspirador coronel Martín Alonso, y «representante regional de

61. Causa 37-37, op.cit, f. 82V.

62. Ibidem, f. $58 \mathrm{~V}$ 
la UME ${ }^{63}$. Las fuentes consultadas desmienten que Tovar fuera el representante de la UME. Había mantenido algún contacto con esa organización, pero optado por no integrarse a ella ${ }^{64}$. Según el conspirador comandante Gutiérrez Soto, el teniente coronel Tovar no manifestó su pensamiento (a favor de los sublevados) hasta que el general Salcedo no fue tajante en su rechazo al movimiento militar ${ }^{65}$.

No obstante es cierto que Tovar y el EM, por constituir el entorno más cercano al mando superior, jugaron un papel en la cadena de incidentes que llevó a la destitución de Salcedo y al triunfo de la sublevación en la Octava División. Su lealtad al general quizás flaqueó el 20 de julio al tomar la iniciativa de intentar entrevistarse con el hombre fuerte de los conspiradores, el coronel Martín Alonso. Es posible reconstruir lo ocurrido en la División en La Coruña entre el 18 y el 20 de julio a partir del sumario instruido en agosto de 1936 contra los generales Salcedo (jefe de la División) y Caridad Pita (jefe de la xv Brigada de Infantería), ambos fusilados por adbesión a la rebelión. Las declaraciones de ambos generales ante la justicia de los sublevados ilustran nítidamente los motivos de aquellos mandos superiores que se mantuvieron leales al Gobierno constituido ${ }^{66}$.

La sublevación estalló el día 20 cuando hacia las once de la mañana una veintena de jefes y oficiales convocados a una reunión en el despacho de Salcedo escenificaron un verdadero motín. En una escena de gran violencia verbal y física exigieron al general ponerse al frente de la sublevación y ante la negativa de este le detuvieron ${ }^{67}$.

La presión para que el mando se sumara a la rebelión había aumentado a medida que llegaban noticias de las sublevaciones en las Divisiones del centro y norte (Zaragoza, Valladolid, Burgos). Se habían oído las sirenas de barcos y fábricas del puerto de La Coruña, la Guardia de Asalto se desplegaba para defender el Gobierno Civil. En un ambiente de nerviosismo se llegó a la mañana del lunes 20. Dice Tovar sobre sus preocupaciones la noche anterior:

63. Aróstegui, op. cit., p. 77; Alía, op. cit., p. 91; Cardona, op. cit., p. 30.

64. Archivo General Militar de Ávila, "Información instruida al comandante de Estado Mayor Don Bartolomé Barba con motivo de su paso a las Fuerzas Nacionales», Informes de averiguación de conducta, C. 47097, Cp. 19, según la cual la Octava División no estaba representada en la Junta de la UME, aunque se menciona a Tovar entre los oficiales que tenían conocimiento de la organización.

65. Aimnor, Fondo Coruña, causa 413-36, Enrique Salcedo Molinuevo y Rogelio Caridad Pita, f. $59 \mathrm{~V}-60$.

66. Ibidem, f. 6.

67. Ibídem, f. 2-5V. Se ha planteado la duda de si los oficiales invadieron el despacho de Salcedo para detenerle (De JuAna y PRADA, op. cit., p. 35) o si Salcedo convocó la reunión con intención de imponer su autoridad. Las declaraciones de Tovar y del ayudante de Salcedo confirman la segunda posibilidad (causa 413-36, op. cit, ff. 29V, 420). 
La noche del 19 a 20 la pasó, como las anteriores, en el Estado Mayor de la División, pero intranquilo por las noticias que por las radio-receptoras de esta localidad se recibían principalmente de Sevilla, en las que se decía que sólo faltaban Madrid y Galicia y se apremiaba a éstas para que se levantasen ${ }^{68}$.

Entre las seis y siete de la mañana del 20 el teniente coronel Tovar se presentó en el Cuartel de Infantería acompañado de dos oficiales «para hablar de ello con el coronel del Regimiento n. ${ }^{\circ} 29$ (Martín Alonso)». Este hecho inició la cadena de incidentes que llevó a la crisis del mando en la División. Mientras esperaban a Martín Alonso en el Cuarto de Banderas, por casualidad se presentó el general de la Brigada Rogelio Caridad, que realizaba una de sus rondas para vigilar posibles movimientos sospechosos. El general Caridad, extrañado por la presencia allí de tres oficiales de Em a aquellas horas, dio cuenta de ello al general Salcedo. Al poco rato Salcedo destituye a Tovar, nombrando como nuevo jefe de su EM al comandante Antonio Alonso García, y convoca una reunión de jefes y oficiales. Poco más tarde se produce la escena en el despacho de Salcedo. Dice Tovar se encontraban todos reunidos con el general, en número aproximado de dieciocho a veinte jefes y oficiales, desarrollándose una escena violentísima, debida a la excitación en que todos se encontraban, culminando en la destitución del general Salcedo ${ }^{69}$.

En suma, la actuación del jefe de em fue indirectamente un catalizador de la rebelión pero no se puede afirmar que haya dirigido un movimiento de la oficialidad contra Salcedo ${ }^{70}$. El teniente coronel Tovar continuó ocupando la jefatura de em de la Octava División y fue ascendido a coronel. Murió de enfermedad en febrero de 1938.

\subsection{División de Caballería}

Al frente del em de la División de Caballería se encontraba el teniente coronel José Ungría, figura relevante durante la guerra civil como director del Servicio de Información y Policía Militar (SIPM) el servicio de información de Franco. Ungría había formado parte de la junta de jefes inspirada por la UME en Madrid ${ }^{71}$. Pero en julio de 1936, aunque sabedor de que se pretendía iniciar un movimiento militar, estaba al margen del núcleo que preparaba el alzamiento en Madrid, según testimonio del propio Ungría: "que desde luego tenía noticias del Movimiento aunque él no figuraba oficial ni oficiosamente en la preparación del mismo» y añade que

68. Ibidem, f. 28.

69. Ibidem, f. 29V

70. Aróstegui, op. cit., p. 77; Salas, op. cit., p. 168. Salas cita erróneamente al coronel Teódulo González Peral como jefe de em en La Coruña, en lugar de Tovar. González Peral había sido destinado a La Coruña (DO n. ${ }^{\circ} 56,7$ de marzo 1936) pero no efectuó ese cambio de destino y ocupó la jefatura de em en la Comandancia de Canarias, donde sería cercano colaborador de Franco.

71. Cacho Zabalza, op. cit., p. 37; García Venero, Maximiano, El general Fanjul. Madrid en el Alzamiento Nacional, Madrid: Ediciones Cid, 1967, pp. 104 y ss. 
se encontró por la calle con Álvarez Rementería (delegado de la UME y coordinador del levantamiento en Madrid) quien le expresó que tomarían contacto con él, "cosa que nunca llegaron a efectuar ${ }^{72}$.

Las unidades de la División de Caballería se hallaban dispersas fuera de Madrid, por lo cual su jefe de em José Ungría, aunque sublevado a título individual, en realidad no sublevó a ninguna fuerza ${ }^{73}$. El Gobierno disolvió la División de Caballería el 22 de julio, Ungría se ocultó y en octubre se refugió en la embajada de Francia; pasó a la zona sublevada el 17 de abril de $1937^{74}$.

\subsection{Marruecos: La chispa del 17 de julio}

En el Protectorado de Marruecos existían tres еEмm (en el Cuartel General en Ceuta, en el Cuartel General en Melilla y en la Jefatura Superior en Tetuán). Sus jefes se sumaron a la sublevación, con diferentes grados de entusiasmo, pero ninguno había participado en la conspiración. Emilio Peñuelas, jefe de em del general Romerales en Melilla fue informado sobre el inminente movimiento el 16 de julio, la víspera del día en que estalló ${ }^{75}$. En este apartado nos centraremos en el EM de mayor rango, el de la Jefatura Superior, cuyo jefe coronel Francisco Martín Moreno no fue informado y se encontró con la sublevación como hecho consumado, circunstancia aparentemente paradójica pues Martín Moreno sería más tarde jefe del Em en el Cuartel General de Franco.

La cúpula del mando (el Jefe Superior de las Fuerzas Militares de Marruecos, general Agustín Gómez Morato y los jefes de las Circunscripciones Occidental y Oriental, generales Osvaldo Capaz y Manuel Romerales respectivamente) fue leal al Gobierno ${ }^{76}$. Sin embargo, la mayoría de los jefes con mando de tropas estaban comprometidos con la rebelión, particularmente el teniente coronel Juan Yagüe (Segunda Legión en Ceuta) y el del mismo empleo Carlos Asensio Cabanillas (Regulares de Tetuán). Por esta razón, una vez iniciada en Melilla, la sublevación triunfó sin gran dificultad en el resto del Protectorado.

72. AGHD, declaración de José Ungría Jimenez, sum. 2273, Luis Pérez-Peñamaría Vélez, f. 30.

73. Los dos regimientos de la I Brigada de Caballería en Alcalá de Henares habían sido trasladados a Palencia y a Salamanca en mayo de 1936, a causa de graves incidentes entre la oficialidad y paisanos frentepopulistas. Sobre la División de Caballería el 18 de julio: AGHD, declaración de José Ungría Jiménez, sum. 2273 contra Luis Pérez-Peñamaría Vélez, f. 30. La única fuerza de la División en Madrid era el Regimiento de Artillería a Caballo. En su declaración Ungría recalca que este regimiento dependía directamente del comandante militar del cantón de Campamento (suponemos que así justifica que él no intentara sublevarlo). El general de la División de Caballería Cristóbal Peña Abuín permaneció pasivo.

74. AGMs, hoja de servicios de José Ungría Jiménez, U-199.

75. Fernández de CASTRO, Rafael, Hacia las rutas de una nueva España. Melilla: Artes Gráficas Postal Exprés, 1940, p. 71.

76. El general Osvaldo Capaz se encontraba en Madrid en uso de licencia por enfermedad (SALAS, op. cit., p. 142). 
El mismo día 18 el coronel Martín Moreno -jefe de EM en Tetuán- fue promovido por Franco a la jefatura de EM del Ejército expedicionario de África que se iba a trasladar para operar en la Península. Martín Moreno desempeñó un papel destacado en el Cuartel General del Generalísimo durante la guerra y como jefe del Alto Estado Mayor en la posguerra. Franco le otorgaría más tarde un título nobiliario. Paradójicamente, hay testimonios sobre las iniciales vacilaciones de Martín Moreno ante la sublevación, que indican que había sido ajeno al núcleo conspirativo y que parecen denotar un reflejo inicial de lealtad a las altas autoridades del Protectorado (su jefe directo el general Gómez Morato y el alto comisario Álvarez-Buylla). Dice Gil Honduvilla:

El comportamiento del coronel Martín Moreno en los primeros instantes de la acción armada ha de ser calificado cuanto menos de dudoso [...]. Todo parece indicar que tras unos momentos de desconcierto en los que cumplió las órdenes del Alto Comisario, decidió, cuando la situación mostraba el triunfo de las fuerzas alzadas, pasarse al bando de los vencedores $[\ldots]^{77}$.

Al encontrarse ausente el general Gómez Morato (quien al tener noticia de la rebelión se había desplazado a Melilla, donde fue detenido por los sublevados), el alto comisario había puesto a Martín Moreno al mando de la guarnición de Tetuán. Según un testimonio, una llamada telefónica de Martín Moreno a uno de los principales sublevados (el teniente coronel Asensio) delató su intención inicial de no secundar el golpe. El mismo testimonio continúa diciendo: "Al día siguiente llegó Franco. Le esperaban generales, jefes y oficiales y entre ellos Martín Moreno. Al verle Franco le dio un abrazo especialmente afectuoso y se lo llevó de jefe de Estado Mayor ${ }^{78}$. Martín Moreno continuó a las órdenes del Generalísimo durante toda la guerra y, por ejemplo, le acompañó de Salamanca a Leganés en su viaje al frente de Madrid en noviembre de 1936. Franco había sido en 1935 comandante en jefe en Marruecos durante tres meses, habiendo establecido una excelente relación con Martín Moreno ${ }^{79}$.

\section{CONClusiones}

Un propósito de este trabajo ha sido esclarecer la actuación de las jefaturas de los еЕмм у aproximarse con mayor precisión a las actitudes de la oficialidad del Ejército ante «el cataclismo de julio», como lo calificó Cardona ${ }^{80}$. En este empeño

77. Gil Honduvilla, El 17 a las $17 \ldots$, p. 153.

78. Vegas Latapie, Eugenio, La frustración en la victoria. Madrid: Ed. Actas, 1995, p. 53, citado en Gil Honduvilla, El 17 a las 17..., pp. 153-154; Vegas Latapié cita otro testimonio del mismo Yagüe sobre la oposición de Martín Moreno a la sublevación y a continuación comenta: "Me parece estar aun oyendo a Yagüe, casi a gritos: ¿Por qué no fusilé aquel día a Martín Moreno?. Porque tenía mucho que hacer.»

79. Preston, Paul, Franco, "Caudillo de España». Barcelona: Grijalbo, 2002, p. 137.

80. CARDONA, op. cit., 1986. 
enlazamos con lo expuesto en la introducción sobre la importancia del estudio de los militares de 1936. A pesar de una adhesión a los rebeldes mayoritaria entre los oficiales de nivel intermedio, la fractura en el Ejército fue profunda, aún más en niveles superiores de mando. Y fue para muchos una vivencia traumática, por los lazos de compañerismo y espíritu de cuerpo que unían a la oficialidad.

La hipótesis propuesta en la introducción sobre las actitudes del grupo de coroneles al frente de los еЕмм ha resultado confirmada en gran medida por datos extraídos de un número apreciable de fuentes primarias. Al final de este apartado expondremos conclusiones sobre las posibles causas de la confusión y las afirmaciones erróneas que aparecen en la bibliografía.

La mayoría de los coroneles jefes de los EEMM (en algunos casos tenientes coroneles) tuvieron escasa implicación en la preparación del movimiento militar y, si lo hicieron, se unieron a los golpistas a última hora. Esta conclusión contradice la percepción de historiadores que dan un mayor protagonismo a la jefatura de los еEMм y en general a la oficialidad de Em. A modo de resumen: el coronel Juan Cantero del Em en Sevilla (sublevado según algunos autores) se encontraba el 18 de julio en uso de permiso de verano y no se presentó en su destino en Sevilla hasta tres semanas después. Fue dado de baja del Ejército por su tibieza. El teniente coronel Luis Tovar, en La Coruña, tuvo contacto con representantes de la UME, pero él y otros oficiales de la División optaron por no integrarse en la estructura de esa organización. No hay ningún indicio de que el coronel Juan Quero, del em en Valladolid, participase en la conspiración. Fue sorprendido por la sublevación, a la cual no obstante se sumó. En Burgos el coronel Fernando Moreno Calderón también se sumó a la sublevación, pero no era parte de la conspiración y fue informado del movimiento el mismo día 18 de julio.

De los diez jefes de EM, sólo cuatro se comprometieron directa o indirectamente con la conspiración (Moxó, Montaner, Pérez-Peñamaría y Ungría) y entre ellos, sólo los dos primeros lo hicieron activamente. En el resto de los casos, los conspiradores optaron por no contar con dichos jefes o por evitar el riesgo de informarles de los planes de sublevación, salvo en el último momento. Por ejemplo, contra la idea de un levantamiento en Marruecos preparado por la gran mayoría de los mandos, ninguno de los tres jefes de los eEmm (Tetuán, Ceuta y Melilla) conocieron los planes golpistas salvo uno (Melilla), que lo hizo la víspera del golpe. Paradójicamente, en centros importantes como Valencia y Madrid, la penetración en los еEмм había sido prácticamente nula y si bien había involucrado al jefe del EM en Madrid, coronel Pérez-Peñamaría, lo hizo marginalmente y sin ningún plan concreto.

Los tres no sublevados fueron Peñamaría, Cantero y Machinandiarena. El primero de ellos porque no quiso o no pudo dar el paso, dadas las circunstancias adversas para los golpistas en Madrid. El segundo por falta de entusiasmo ante la rebelión (con el agravante poco después del fusilamiento por los sublevados de su hermano, también coronel, en Badajoz). El tercero, por lealtad a su jefe el general Martínez Monge, que se mantuvo leal. 
La suerte que corrió a la postre este grupo de militares también refleja la diversidad de las circunstancias que vivieron. Entre ellos, sólo fue fusilado Manuel Moxó, en Barcelona (ejecución extralegal). Juan Cantero en Sevilla fue depurado (retirado en 1936). Peñamaría y Machinandiarena, procesados primero por los republicanos y después por los franquistas. Al primero, tras una pena leve por negligencia, se le aplicó el retiro forzoso en 1941. El segundo, condenado a seis años y separado del servicio. Luis Tovar ascendió a coronel pero murió de enfermedad en 1938. Juan Quero en Valladolid, se encontraba a pocos años del retiro y tuvo un fin de carrera discreto. No así Moreno Calderón, que ocupó cargos relevantes en el ejército de Franco y alcanzó el grado de general de división, aunque tuvo que superar un consejo de guerra por una denuncia sobre su actitud ambigua el 18 de julio. En Tetuán, el coronel Martín Moreno se integró al Em del Generalísimo y tuvo una brillante carrera en la posguerra. Caso paradójico ya que, al parecer, Yagüe estuvo a punto de fusilarlo por su inicial oposición a los sublevados ${ }^{81}$.

Podemos preguntarnos por qué encontramos errores o ausencia de matices en la bibliografía. En el caso que hemos tratado, nuestra opinión es que se deben a dos causas principales. Por un lado, el hecho de que hasta tiempos relativamente recientes no se hallaban fácilmente disponibles los fondos archivísticos que hemos utilizado en esta investigación. O bien, aunque dichos fondos se hallasen al menos parcialmente disponibles, su relevancia y riqueza documental no había sido puesta de relieve entre la comunidad investigadora.

El otro aspecto que ha tenido un efecto en la historiografía sobre los militares es una visión simplista de las adhesiones a los bandos en liza en la guerra civil, quizás influida por la visión franquista impuesta en la posguerra: que el Ejército español, como una gran familia, permaneció unido e indivisible en su papel de salvador de la Patria contra enemigos exteriores e interiores ${ }^{82}$. Aquellos militares que no se habían unido a los sublevados eran contados casos de comportamiento anormal y deshonroso. Por tanto, lo «normal» es que un militar fuera partidario de los sublevados. En unas memorias publicadas en 1945, un militar «intelectual», el general monárquico Alfredo Kindelán, habla de «el corto número de generales y jefes que con deshonor o debilidad inexplicable quedaron del lado de los rojos ${ }^{83}$. Este marco mental pudo haber perdurado en parte de la historiografía hasta bien entrados los años de la transición democrática. Desde otros parámetros ideológicos, un prejuicio antimilitarista puede llevar a una visión parecida, considerando que un militar debía ser, prácticamente por definición, partidario de la sublevación ${ }^{84}$.

81. Gil Honduvilla, op. cit., pp. 153-154.

82. La idea del Ejército como exclusivo intérprete y custodio de la Patria: Velasco-MarTínez, $L a$ Nación Marcial..., p. 189.

83. Kindelán, Alfredo, Mis cuadernos de guerra. Barcelona: Planeta, 1982 (1. a edición 1945, Editorial Plus), p. 194.

84. Un estudio clásico sobre la caracterización del militar profesional y las relaciones cívicomilitares: Huntington, Samuel P.: The soldier and the state. The theory and politics of civil-military 
Ante la crisis del 18 de julio, una parte de la oficialidad, minoritaria pero más significativa lo que parte de la historiografía ha considerado, fue reacia a violentar la legalidad constituida. Más que por razones ideológicas, en muchos casos la adhesión a los sublevados se produjo como reacción de obediencia debida, de resignación, de supervivencia, o simplemente de adaptación a los hechos consumados.

relations. Cambridge: Harvard UP, 1957, pp. 59 y ss., citada en VelasCo-MarTínez, Luis, La Nación Marcial..., pp. 109-110. 
